\title{
Clopidogrel was effective in patients who have MI with ST segment elevation receiving aspirin and fibrinolytic therapy
}

Sabatine MS, Cannon CP, Gibson CM, et al. Addition of clopidogrel to aspirin and fibrinolytic therapy for myocardial infarction with ST-segment elevation. N Engl J Med 2005;352:1179-89.

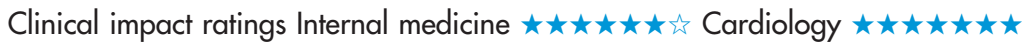

matients who have myocardial infarction (MI) with ST segment elevation and are receiving aspirin and standard fibrinolytic therapy, is the addition of clopidogrel beneficial?

Design: randomised controlled trial (Clopidogrel as Adjunctive Reperfusion Therapy [CLARITY]-Thrombolysis in Myocardial Infarction [TIMI] 28 Study).

Allocation: concealed. *

Blinding: blinded (patients and healthcare providers).*

Follow up period: to the start of coronary angiography (median $3.5 \mathrm{~d}$ ), or in patients not having angiography, to hospital discharge or day 8 , whichever came first.

Setting: 319 sites in 23 countries.

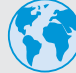

Patients: 3491 patients who were 18-75 years (mean age 57 y, $80 \%$ men); presented within 12 hours after the onset of ischaemic discomfort at rest lasting $>20$ minutes; had ST segment elevation of $\geqslant 0.1 \mathrm{mV}$ in $\geqslant 2$ contiguous limb leads, ST segment elevation of $\geqslant 0.2 \mathrm{mV}$ in $\geqslant 2$ contiguous precordial leads, or left bundle branch block that was not known to be old; and were scheduled to receive a fibrinolytic agent, aspirin, and heparin if a fibrin specific lytic agent was prescribed. Exclusion criteria included clopidogrel use in the previous 7 days, planned clopidogrel or glycoprotein Ilb/Illa inhibitor treatment before angiography, cardiogenic shock, and previous coronary artery bypass grafting.

D Intervention: clopidogrel, $300 \mathrm{mg}$ loading dose and then $75 \mathrm{mg}$ once daily ( $n=1752)$, or placebo $(n=1739)$, up to and including the day of coronary angiography (48-192 h after the start of study medication). Patients not having angiography had the study medication for 8 days or until hospital discharge.

Outcomes: primary outcome was composite of an occluded infarct related artery (TIMI flow grade 0 or 1 ), recurrent $\mathrm{MI}$ before angiography, or all cause mortality before angiography could be done. Other outcomes included rate of major bleeding.

ac Patient follow up: $100 \%$ (intention to treat analysis).

*See glossary.

\section{MAIN RESULTS}

3283 patients (94\%) had angiography. Patients receiving clopidogrel had lower rates of the composite primary outcome and rates of an occluded infarct related artery than those receiving placebo, but the groups did not differ for rates of recurrent MI or all cause mortality (table). The clopidogrel and placebo groups did not differ for rates of major bleeding through the day after angiography $(1.3 \% \vee 1.1 \%$, $\mathrm{p}=0.64)$ or at 30 days $(1.9 \% \vee 1.7 \%, \mathrm{p}=0.80)$.

\section{CONCLUSION}

In patients who have myocardial infarction (MI) with ST segment elevation and are receiving aspirin and standard fibrinolytic therapy, For correspondence: Dr M S Sabatine, Brigham and Women's Hospital and Harvard Medical School, Boston, MA, USA. msabatine@partners.org Sources of funding: Sanofi-Aventis and Bristol-Myers Squibb and National Heart, Lung and Blood Institute. the addition of clopidogrel lowered the composite rate of an occluded infarct related artery, recurrent $\mathrm{MI}$, or all cause mortality.

Clopidogrel $v$ placebo in addition to aspirin and standard fibrinolytic therapy for myocardial infarction (MI) with ST segment elevation*

\begin{tabular}{|c|c|c|c|c|}
\hline $\begin{array}{l}\text { Outcomes at } \\
\text { mean } 3.5 \text { days }\end{array}$ & Clopidogrel & Placebo & $\begin{array}{l}\text { RRR } \\
(95 \% \mathrm{Cl})\end{array}$ & NNT (Cl) \\
\hline \multirow{4}{*}{$\begin{array}{l}\text { Composite } \\
\text { primary } \\
\text { outcome } \\
\text { Occluded infarct } \\
\text { related artery } \\
\text { Recurrent } \\
\text { myocardial } \\
\text { infarction }\end{array}$} & $15 \%$ & $22 \%$ & $\begin{array}{l}31 \% \\
(20 \text { to } 40)\end{array}$ & 15 (11 to 24$)$ \\
\hline & $12 \%$ & $18 \%$ & $\begin{array}{l}64 \% \\
(54 \text { to } 75)\end{array}$ & 15 (11 to 24$)$ \\
\hline & $2.5 \%$ & $3.6 \%$ & $\begin{array}{l}30 \% \\
(-3 \text { to } 52)\end{array}$ & Not significant \\
\hline & & & RRI (CI) & NNH \\
\hline $\begin{array}{l}\text { All cause } \\
\text { mortality }\end{array}$ & $2.6 \%$ & $2.2 \%$ & $\begin{array}{l}18 \% \\
(-23 \text { to } 80)\end{array}$ & Not significant \\
\hline
\end{tabular}

*Abbreviations defined in glossary; RRR, RRI, NNT, NNH, and $\mathrm{Cl}$ calculated from data in article.

†Composite primary outcome $=$ an occluded infarct related artery, recurrent $\mathrm{Ml}$, or all cause mortality.

\section{Commentary}

n patients with ST-segment elevation $\mathrm{Ml}$, recent efforts to improve upon a regimen of aspirin, thrombolysis, and heparin have met with frustration because aggressive antiplatelet strategies, primarily with glycoprotein $\mathrm{Ilb} / \mathrm{llla}$ receptor antagonists, have caused unacceptably high rates of haemorrhage. ${ }^{2}$ The CLARITY-TIMI 28 Investigators used the simple and elegant addition of clopidogrel to the triple therapy and achieved benefit without any clinically relevant excess bleeding. Unfortunately, the trial excluded patients $>75$ years of age; thus the population most at risk and vulnerable to haemorrhage was not studied. In fact, early hospital mortality was $<3 \%$, so the population was quite low risk. The trial was powered only for a composite endpoint, and the chief benefit was better coronary patency at catheterisation several days after admission. However, this surrogate is well established as a strong correlate with late left ventricular remodelling and survival, so a safe treatment enhancing this outcome is attractive.

Given the safety and clear benefit on coronary patency, the CLARITYTIMI 28 trial appears to show that the addition of clopidogrel to aspirin, heparin, and thrombolytic therapy is an appropriate standard of care for younger patients who may have delayed catheterisation by several days. Because urgent angiography and primary angioplasty remain unavailable to a large number of patients worldwide and in the US with STsegment elevation, thrombolysis will continue to be used, now with a safe, beneficial, and inexpensive adjunct. Steven Borzak, MD
Florida Cardiovascular Research, LC Atlantis, Florida, USA

1 ASSENT-3 Investigators. Lancet 2001;358:605-13.

2 Topol EJ. Lancet 2001;357:1905-14. 